\title{
Analysis of the Possibilities of Improving the Selected Properties Surface Layer of Butt Joints Made Using the FSW Method
}

\author{
Magdalena Bucior ${ }^{1 *}$, Rafał Kluz' ${ }^{1}$ Andrzej Kubit' ${ }^{1}$, K. Ochał $^{1}$ \\ 1 Rzeszow University of Technology, Faculty of Mechanical Engineering and Aeronautics, al. Powstańców \\ Warszawy 8, 35-959 Rzeszów, Poland \\ * Corresponding author's e-mail: magdabucior@prz.edu.pl
}

\begin{abstract}
The paper presents the results pertaining to an analysis on the influence of technological parameters of pneumatic shot peening technology on the selected properties of a surface layer of butt joints made with Friction stir welding (FSW) method. Butt joints made of two 2024-T3 aluminum alloy sheets with the thickness of $1 \mathrm{~mm}$ were shot peened with glass beads. The experiments were carried out according to the statistical 3-level completed plan PS/DC $3^{2}$. The technological parameters were changed in the range: pressure $\mathrm{p}=0.4-0.6 \mathrm{MPa}$ and peening time $t=1-3 \mathrm{~min}$. As a result of the conducted research, adequate equations describing the effect of the analyzed parameters on the surface roughness were obtained. Shot peening with glass beads significantly reduced the surface roughness from $\mathrm{Ra}=5.2 \mu \mathrm{m}$ to $\mathrm{Ra}=1.42 \mu \mathrm{m}$. This treatment provides high compressive residual stresses and the increase of the surface layer hardness. The results show that shot peening is a highly efficient and cost-effective mechanical treatment used for improving the mechanical properties of the butt joints made with the FSW method.
\end{abstract}

Keywords: shot peening, FSW (friction stir welding), 2024, aluminum alloy

\section{INTRODUCTION}

Friction stir welding (FSW) is a promising solid state process for joining materials, especially when used on the high strength aerospace aluminum alloys that are difficult to weld [1]. The advantages of this method can include, first of all, the ease of obtaining joints with high, repeatable mechanical and structural properties. This method can even be used to perform very long welds which are free from cracks and porosity and do not require the post-weld cleaning. In addition, common faults such as cracking associated with a conventional light metal welding process are eliminated during welding with this method. One of the significant disadvantages of FSW is the appearance of inexpedient tensile stresses. The residual stress in the weld can result in a crack formation and propagation [2]. The surface treatment, such as shot peening (SP), is one of the methods used for mitigating tensile weld residual stresses. This process causes a beneficial compressive residual stress, strain hardening and improves the fatigue strength of various materials $[3,4]$. The SP process can be used to eliminate the costs associated with the quality control of a welding process, as well as other costs associated with the removal of a flow arm by milling [5]. The studies on the impact of various shot peening techniques, such as, for example: shot peening [3, 4], laser peening $[2,6,7]$, cavitation shot peening [4, 8] or ultrasonic peening [9] on the properties of joints made with the FSW method can be found in the literature. The most commonly reported basic parameters characterizing the state and properties of the surface layer of the welded butt joints include the following: a stereometric state of the surface, microhardness and a state of stress. The authors of the work [10] examined the effect of $\mathrm{SP}$ on the mechanical properties in the friction stir welded joints of 6061-T6 aluminum alloy. The study shows that shot peening has beneficial effects on the fatigue strength, microhardness and 
residual stresses. The best results were obtained for the joints after SP performed with spherical ceramic shots (Z300), and Almen intensity of 0.24 A. Ali et al. [5] studied the effect of the controlled shot peening (CSP) on the fatigue behavior of 2024-T3 aluminum friction stir welds. CSP delivers a significant improvement in terms of a fatigue life. The tensile residual stresses introduced in the thermo-mechanically affected zone (TMAZ) during FSW were changed to compressive stresses after SP performed with shot S230 and Almen intensity of $14 \mathrm{~A}$. In turn, Hatamleh et al. $[2,6]$ compared two peening methods: laser and shot peening. These techniques were used to introduce a compressive residual stress into FSW 7075-T7351 and 2195-T8 aluminum alloys. The surface residual stresses resulting from SP on both alloys were higher when compared to laser peening. Likewise, Liu et al. [11] presented the properties in the weld surface of FSW 7050-T7451 aluminum alloys after laser peening. The results of the tests indicated that hardness increased after laser peening by $9 \mathrm{HV}$. The fatigue life after this treatment was increased by $30 \%, 27 \%$ and $5 \%$ when the loading stress was $200 \mathrm{MPa}, 250 \mathrm{MPa}$ and $300 \mathrm{MPa}$, respectively. The residual stress in the weld zone (WZ) generated a compressive residual stress that reached the largest value of $100 \mathrm{MPa}$, after this treatment. Kawashima et al. [7] studied the effect of femtosecond laser peening on the mechanical properties of base and FSW 7075 aluminum alloys. They concluded that femtosecond laser peening enhanced the fatigue strength of the FSW specimen by approximately $15 \mathrm{MPa}$ compared to that of the base metal. This technique increased the surface hardness and induced a compressive residual stress of approximately $-330 \mathrm{MPa}$ on the surface of FSW specimen.

The surface roughness is another important parameter affecting the surface quality of a component because a significant proportion of a component failure already starts on the surface due to discontinuity. The authors of the work [12] focused on the surface roughness in the peened FSW 2195-T8 aluminum alloy. They observed that peening with glass beads with a diameter of $0.59 \mathrm{~mm}$ caused a significant increase in the surface roughness compared to laser peening and non-peened surfaces. The authors of the papers $[2,5 \div 7,10 \div 12]$ mainly focused on the study of the impact of peening methods on the mechanical properties of the joints welded with FSW method. Most of them follow traditional experimental methods i.e. varying one peening parameter at a time while other parameters remain constant. This conventional parametric design of an experiment approach is time consuming. The selection of appropriate technological parameters of the shot peening process is an important issue because wrong parameters can cause numerous defects and cracks, thus they may reduce the strength of the connection. Therefore, the shot peening studies were performed according to the complete statistical plan PS/DC $3^{2}$. This plan is an effective tool for identifying significant factors by conducting a relatively smaller number of experiments.

In this work, the shot peening method was used in order to improve the properties of the butt joints of 2023-T3 aluminum alloy welded structure. The experiments were conducted according to the statistical 3-level completed plan PS/DC $3^{2}$. The roughness, residual stresses and microhardness were analyzed after SP.

\section{METHOD}

The effect of the selected technological parameters of shot peening on the roughness, residual stress and microhardness after FSW process were examined with $1 \mathrm{~mm}$ thick sheets made of 2024-T3 aluminum alloy. The chemical composition and mechanical properties are presented in Tables 1 and 2, respectively. 2024 aluminum alloy in T3 state belongs to the group of hardly workable materials with low resistance to oxidation. It is used mainly in aviation for the elements of aircraft equipment, such as: steering columns, seat frames, covers, turn-over mechanisms as well as for structural elements such as: plating of wings, fuselage, carriers or control rods

The FSW process was carried out on a universal vertical milling machine with the use of a tool in the shape of a pin with a helix on the end (Fig. 1). Two sheets, $1 \mathrm{~mm}$ thick, were butt-welded

Table 1. Chemical composition of the 2024 aluminum alloy (wt $\%$ ).

\begin{tabular}{|c|c|c|c|c|c|c|c|c|}
\hline $\mathrm{Zn}$ & $\mathrm{Fe}$ & $\mathrm{Ti}$ & $\mathrm{Cr}$ & $\mathrm{Mg}$ & $\mathrm{Mn}$ & $\mathrm{Cu}$ & $\mathrm{Si}$ & $\mathrm{Al}$ \\
\hline $0.25 \max$ & $0.5 \max$ & $0.15 \max$ & $0.1 \max$ & $1.2 \div 1.8$ & $0.3 \div 0.9$ & $3.8 \div 4.9$ & $0.5 \max$ & rest \\
\hline
\end{tabular}


Table 2. Mechanical properties of 2024-T3 aluminum alloy.

\begin{tabular}{|c|c|c|}
\hline $\begin{array}{c}\text { Tensile stress } R_{m} \\
(\mathrm{MPa})\end{array}$ & $\begin{array}{c}\text { Yield stress } R_{e} \\
(\mathrm{MPa})\end{array}$ & Elongation $A(\%)$ \\
\hline $360 \div 425$ & $250 \div 290$ & $12 \div 14$ \\
\hline
\end{tabular}

in a perpendicular direction to the line of the weld formed. The welding tests were carried out for the following parameters: rotational speed $\mathrm{n}=1300 \mathrm{rpm}$, feed rate $\mathrm{f}=50 \mathrm{~mm} / \mathrm{min}$, inclination angle of the tool of $3^{\circ}$. Next, the $12.5 \mathrm{~mm}$ test specimens were cut from the welded sheets (Fig. 2).

In order to improve the properties of the joints made with the FSW method, they were subjected to the SP process in accordance with the research plan PS / DK $3^{2}$ (Table 3).

The plan of the experiment assumes the adoption of three levels of control factors coded as $\mathrm{x}$ [13]:

- the minimum (-),

- the central $(0)$,

- the maximum $(+)$.

The main aim of the test was to attain an adequate mathematical model in the form of the second degree polynomial with a significance level of $\alpha=0.05$ :

$y=b_{o}+\sum b_{k} x_{k}+\sum b_{k k} x_{k}^{2}+\sum b_{k j} x_{k} x_{j}$

where: $x_{k}, x_{j}$-input factors, $b_{o}, b_{k}, b_{k k}, b_{k j}$-regression function coefficients, $y$ - an output factor (measured value).
Pneumatic shot peening was carried out on a special device designed for this type of tests. The technological parameters were changed in the range: shot peening time $\mathrm{t}=1 \div 3 \mathrm{~min}$ and pressure $\mathrm{p}=0.4 \div 0.6 \mathrm{MPa}$. The diameter of the glass beads, which was in the $d_{b}=500 \div 900 \mu \mathrm{m}$ range, was a constant parameter in the experiment. The distance of the specimen to the nozzle was $1=250 \mathrm{~mm}$.

The geometric surface structure investigations were carried out using the Talysurf CCI Lite optical profilometer according to ISO 4287 [14]. The tests included measurements of the selected roughness parameters, profilograms, 3D views and contour maps. The residual stress was measured with non-destructive methods. The X-ray diffractometer Proto iXRD Combo and computer software XRD Win 2.0 by Proto Manufacturing were used for this research. The research was carried out at the Department of Materials Science at Rzeszow University of Technology. The measurements were conducted in a longitudinal and transverse direction on a weld center before and after shot peening for some variants. The $\sin ^{2} \Psi$ [15] method was used to calculate the values of residual stresses at a given measurement point. This is a standard method based on the use of Bragg-Brentan symmetrical diffraction. This method uses $\Psi$ type goniometer which enables to obtain appropriate inclinations of a diffraction vector by angles $\Psi_{i}$ in the plane perpendicular to the diffraction plane [16]. A lamp with a chrome anode and a beam of characteristic radiation $\mathrm{CrK} \alpha$ with a wave length $\lambda=2.291 \AA$ with

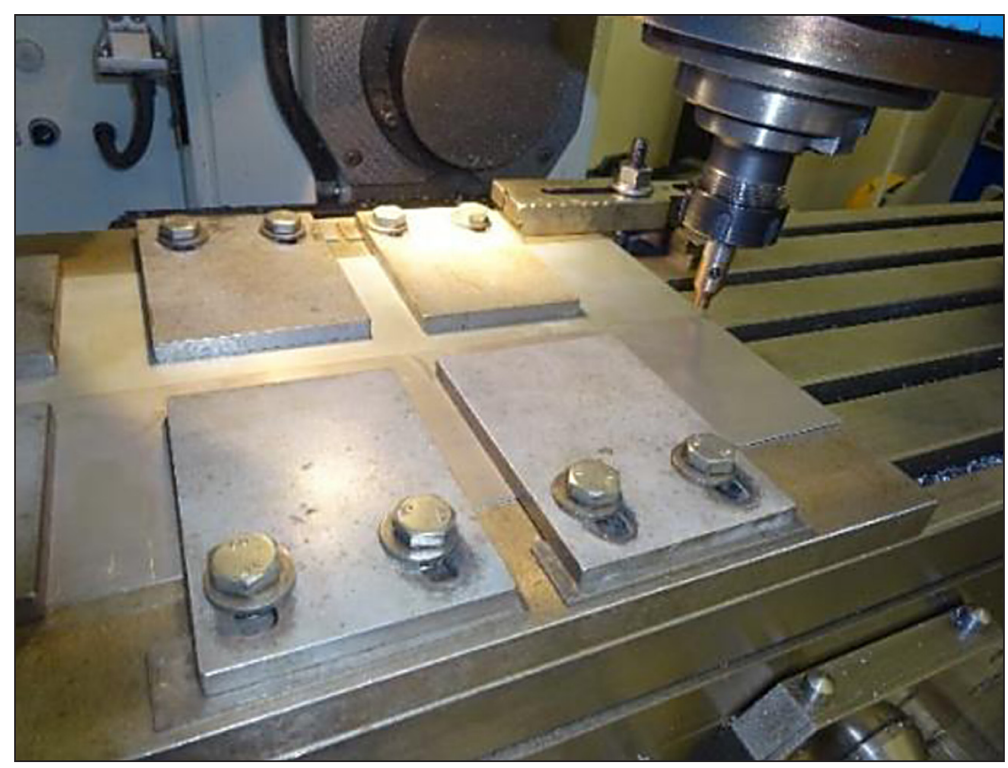

Fig. 1. Friction stir welding set-up 


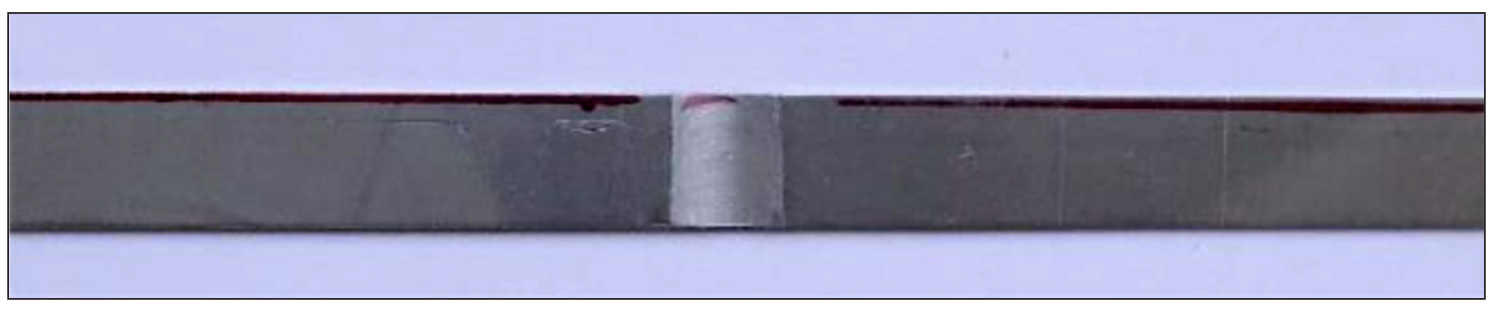

Fig. 2. The sample used in the shot peening treatment

Table 3. Matrix of PS/DC $3^{2}$ plan

\begin{tabular}{|c|c|c|c|c|c|c|}
\hline No. & $\mathrm{x}_{0}$ & $\mathrm{x}_{1}$ & $\mathrm{x}_{2}$ & $\mathrm{x}_{1}{ }^{2}$ & $\mathrm{x}_{2}{ }^{2}$ & $\mathrm{x}_{1} \mathrm{x}_{2}$ \\
\hline 1 & + & + & + & + & + & + \\
\hline 2 & + & + & 0 & + & 0 & 0 \\
\hline 3 & + & + & - & + & + & - \\
\hline 4 & + & 0 & + & 0 & + & 0 \\
\hline 5 & + & 0 & 0 & 0 & 0 & 0 \\
\hline 6 & + & 0 & - & 0 & + & 0 \\
\hline 7 & + & - & + & + & + & - \\
\hline 8 & + & - & 0 & + & 0 & 0 \\
\hline 9 & + & - & - & + & + & + \\
\hline
\end{tabular}

where: $x_{1}-$ coded value of time $\mathrm{t}$, $x_{2}-$ coded value of pressure $\mathrm{p}$,

a collimator diameter of $2 \mathrm{~mm}$ was used in the tests. The anode current was $4 \mathrm{~mA}$, and the anode voltage was $20 \mathrm{kV}$. The stresses were determined for the constant values of the angle $\Psi$ in the range within $25^{\circ}$ to $-25^{\circ}$. Elastic deformation in the studied part was carried out for a diffraction line from the plane family $\{311\}$ at the angle of $2 \theta=139.3^{\circ}$. The values of Poisson's ratio $v=0.33$ and Young's modulus E $=73.1 \mathrm{GPa}$ [17] were used in the measurements of the residual stress. A Vickers microhardness tester PMT-3 was used to measure the hardness distribution according to ISO 6507 - 1: 2005 [18]. The microhardness of the FSW and SP samples was measured across the weld zone at the distance of $0.15 \mathrm{~mm}$ from the top of the weld joint. The applied load was $\mathrm{F}=2.94 \mathrm{~N}$, for the time of $10 \mathrm{~s}$.

\section{RESULTS AND DISCUSSION}

\section{Surface roughness}

The average values of the selected roughness parameters of the joint made with the FSW method after SP with glass beads for different parameters of a strengthening process and for the base variant (surface after welding) according to the plan PS/DC $3^{2}$ are shown in Table 4. The examples of the roughness profiles for the selected variants presented in Figure 3 and Table 5 show a 3D view of the surface, contours maps and selected parameters of 5 variants.

The presented surface roughness tests results showed that shot peening with glass beads has a positive effect on the condition of the surface layer of the joints made with the FSW method. The most frequently quoted roughness parameters used to assess the surface condition after SP include the Ra parameter describing an average

Table 4. Average values of the selected surface roughness parameters obtained after a shot peening process according to plan PS/DC $3^{2}$

\begin{tabular}{|c|c|c|c|c|c|c|c|c|c|c|}
\hline \multirow[b]{2}{*}{ No. } & \multicolumn{2}{|c|}{ Input factors } & \multicolumn{8}{|c|}{ Output factors } \\
\hline & $\begin{array}{c}\mathrm{t} \\
\min \end{array}$ & $\begin{array}{c}\mathrm{p} \\
\mathrm{MPa}\end{array}$ & $\begin{array}{l}\mathrm{Rp} \\
\mu \mathrm{m}\end{array}$ & $\begin{array}{l}\mathrm{Rv} \\
\mu \mathrm{m}\end{array}$ & $\begin{array}{l}\mathrm{Rz} \\
\mu \mathrm{m}\end{array}$ & $\begin{array}{l}\mathrm{Rt} \\
\mu \mathrm{m}\end{array}$ & $\begin{array}{l}\mathrm{Ra} \\
\mu \mathrm{m}\end{array}$ & $\begin{array}{l}\mathrm{Rq} \\
\mu \mathrm{m}\end{array}$ & Rsk & Rku \\
\hline $0^{*}$ & - & - & 11.65 & 12.56 & 24.20 & 29.13 & 5.20 & 6.12 & -0.04 & 2.27 \\
\hline 1 & 3 & 0.6 & 4.63 & 4.55 & 9.17 & 13.47 & 1.62 & 2.06 & -0.11 & 3.19 \\
\hline 2 & 3 & 0.5 & 4.12 & 4.61 & 8.74 & 10.94 & 1.63 & 1.97 & -0.10 & 2.50 \\
\hline 3 & 3 & 0.4 & 3.95 & 4.08 & 8.05 & 10.83 & 1.42 & 1.77 & 0.05 & 2.77 \\
\hline 4 & 2 & 0.6 & 4.98 & 5.10 & 10.10 & 14.73 & 1.69 & 2.13 & -0.20 & 3.45 \\
\hline 5 & 2 & 0.5 & 6.66 & 5.12 & 11.77 & 18.83 & 2.16 & 2.73 & 0.32 & 2.90 \\
\hline 6 & 2 & 0.4 & 4.93 & 5.61 & 10.55 & 16.80 & 1.77 & 2.30 & -0.13 & 3.26 \\
\hline 7 & 1 & 0.6 & 7.67 & 7.10 & 14.77 & 23.03 & 2.82 & 3.47 & 0.09 & 2.39 \\
\hline 8 & 1 & 0.5 & 5.49 & 5.25 & 10.77 & 14.47 & 1.94 & 2.39 & 0.21 & 2.59 \\
\hline 9 & 1 & 0.4 & 6.21 & 4.92 & 11.13 & 15.60 & 2.19 & 2.71 & 0.29 & 2.69 \\
\hline
\end{tabular}

$0 *$ - base variant (before shot peening) 
a)

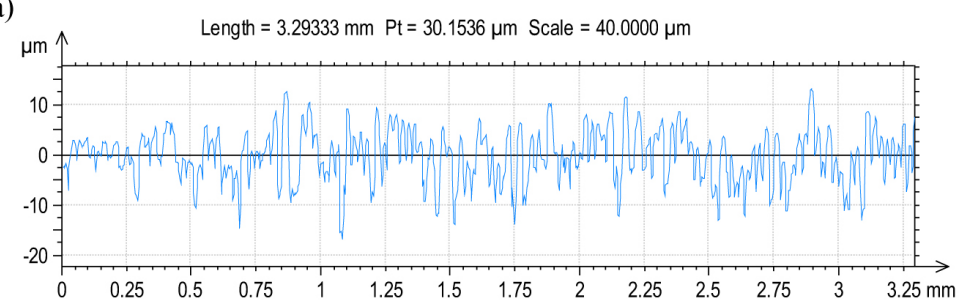

b)

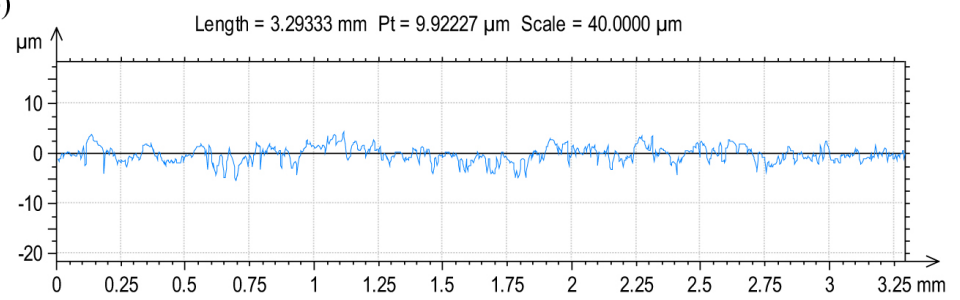

c)

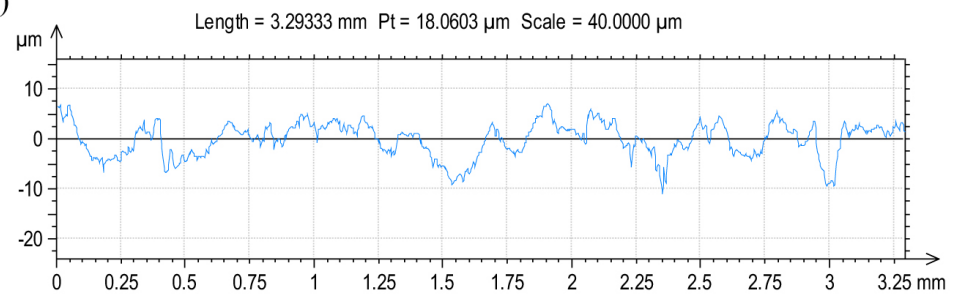

Fig. 3. Roughness profile for a) base variant, b) 3 variant, c) 7 variant

arithmetic deflection of the roughness profile and the Rz parameter representing the profile height according to ten points. The lowest roughness value was obtained for the SP time $\mathrm{t}=3 \mathrm{~min}$ and the pressure $\mathrm{p}=0.4 \mathrm{MPa}$ (variant 3 ), where $\mathrm{Ra}$ and $\mathrm{Rz}$ were $\mathrm{Ra}=1.42 \mu \mathrm{m}$ and $\mathrm{Rz}=8.05 \mu \mathrm{m}$, which is a decrease by $73 \%$ for Ra and by $67 \%$ for $\mathrm{Rz}$, respectively, compared to the base variant. In turn, the highest value of the $\mathrm{Ra}$ and $\mathrm{Rz}$ parameters was obtained for the variant No. 7 $(\mathrm{t}=1$ min. $\mathrm{p}=0.6 \mathrm{MPa})$, where $\mathrm{Ra}=2.82 \mu \mathrm{m}$ and $\mathrm{Rz}=14.77 \mu \mathrm{m}$, which is a decrease of $46 \%$ for $\mathrm{Ra}$ and $39 \%$ for Rz compared to the surface after welding. While analyzing the presented results, it can be noticed that the smallest roughness was obtained for the peening time $t=3 \mathrm{~min}$ (variant 1-3). Reducing the shot peening time increases the surface roughness. For the variants $1-3,7$ and for the base sample, the topographic maps and the selected amplitude parameters were presented. The topographic maps (Table 3a) show a significant difference between the shot peened surface and the surface after welding with the FSW method. The process of SP results in the reduction of sharp peaks in the unevenness of the surfaces created during the welding. The surfaces, according to the variants 2 and 3 , do not have the remains of the roughness tops from the preceding operation, so they are surfaces typical for shot peening. The values of the Sa parameter (average arithmetic deflection of the surface roughness) for these variants are in the range of $\mathrm{Sa}=1.643-1.982 \mu \mathrm{m}$, which is a decrease in the range of $56-63 \%$ compared to the sample after welding, where $\mathrm{Sa}=4.5 \mu \mathrm{m}$. The contour maps (Table $3 b$ ) also confirm that the highest degree of the surface coverage after SP, amounting to more than $90 \%$, was obtained for the time of peening $\mathrm{t}=3 \mathrm{~min}$ and the pressure in the range of 0.4-0.5 MPa.

As a result of the regression, a functional relation between the process parameters $(t, p)$ and the values of height roughness parameters $(\mathrm{Rp}, \mathrm{Rv}$, $\mathrm{Rz}, \mathrm{Rt}, \mathrm{Ra}, \mathrm{Rq}$, Rsk, Rku) were determined.

The obtained relations are described with the following equations (Eq. $2 \div 9$ ):

$$
R p=7.763-1.111 t
$$

$R v=0.414+1.464 t+12.1 p-4.27 t p$

$R z=4.381+1.356 t+19.75 p-6.28 t p$

$$
R t=13.813+5.287 t-2.066 t^{2}
$$


Table 5. The results of surface texture parameters a) a 3D view, b) a contour map

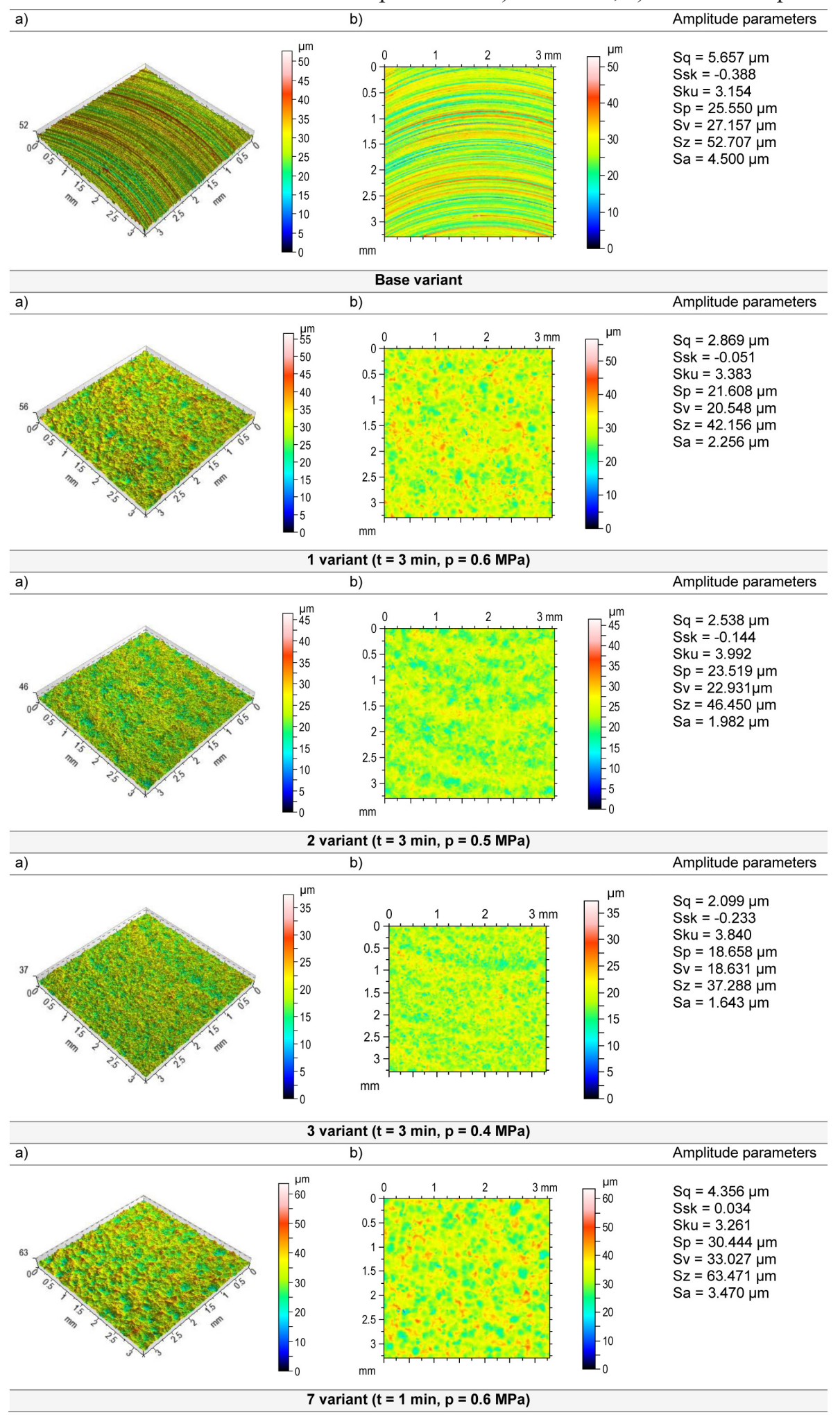

$$
\begin{array}{rlrl}
R a=2.631-0.382 t & \text { (6) } & R k u & =8.322+2.06 t-29.5 p- \\
R q=3.281-0.462 t & \text { (7) } & 0.515 t^{2}+29.5 p^{2}
\end{array}
$$

$$
R s k=-3.30-0.125 t+14.2 p-14.2 p^{2}
$$

While analyzing the obtained equations, it can be concluded that both analyzed technological parameters of the shot peening process (time 
and pressure) had an effect on the roughness of the joints made with the FSW method. The time of peening had a significant influence on the amplitude parameters such as Rp, Rt, Ra and Rq. However, in the case of Rv, Rz, Rsk and Rk parameters, pressure played a significant role.

\section{Residual stress}

Figures 4 and 5 illustrate the residual stresses in a longitudinal $\left(\sigma_{\mathrm{y}}\right)$ and transverse $\left(\sigma_{\mathrm{x}}\right)$ direction for some variants. The measurements of the residual stresses were made on a weld center. The results show that after welding with the FSW method in a longitudinal direction, unfavorable tensile residual stresses, reaching $\sigma_{\mathrm{y}}=5.46 \mathrm{MPa}$, were created. In turn, shot peening caused compressive residual stresses with relatively large values reaching $\sigma_{\mathrm{y}}=-166.15 \mathrm{MPa}$ on the surface layer. For the peened variants, there is a minor difference in the residual stress values between the longitudinal and transverse directions. The direction of the stress measurement is important in the case of the welded surface, where a significant difference between the measurements can be observed. Compressive stresses of $\sigma_{x}=-64.24 \mathrm{MPa}$ were observed in the transverse welding direction for the base variant. While analyzing the presented variants after burnishing, it can be concluded that the most favorable stresses were obtained for the time of peening $\mathrm{t}=3 \mathrm{~min}$ and the pressure $\mathrm{p}=0.4 \mathrm{MPa}$ (variant 3), where $\sigma_{\mathrm{x}}=-169.06 \mathrm{MPa}$ and $\sigma_{\mathrm{y}}=-166.15 \mathrm{MPa}$. In turn, the lowest values of the shot peening stress were observed for the variant $1(\mathrm{t}=3 \mathrm{~min}, \mathrm{p}=0.6 \mathrm{MPa})$, where $\sigma_{\mathrm{x}}=-93.72 \mathrm{MPa}$ and $\sigma_{\mathrm{y}}=-121.18 \mathrm{MPa}$. Shot peening causes a favorable compressive stress increase from 31 to $62 \%$ in the transverse direction, and about $95 \div 97 \%$ in the longitudinal direction, compared to the stress of the FSW method.

Figure 6 presented the distribution of microhardness profiles across the weld zone at the distance of $0.15 \mathrm{~mm}$ from the top of the weld joint for some variants. The results indicate that

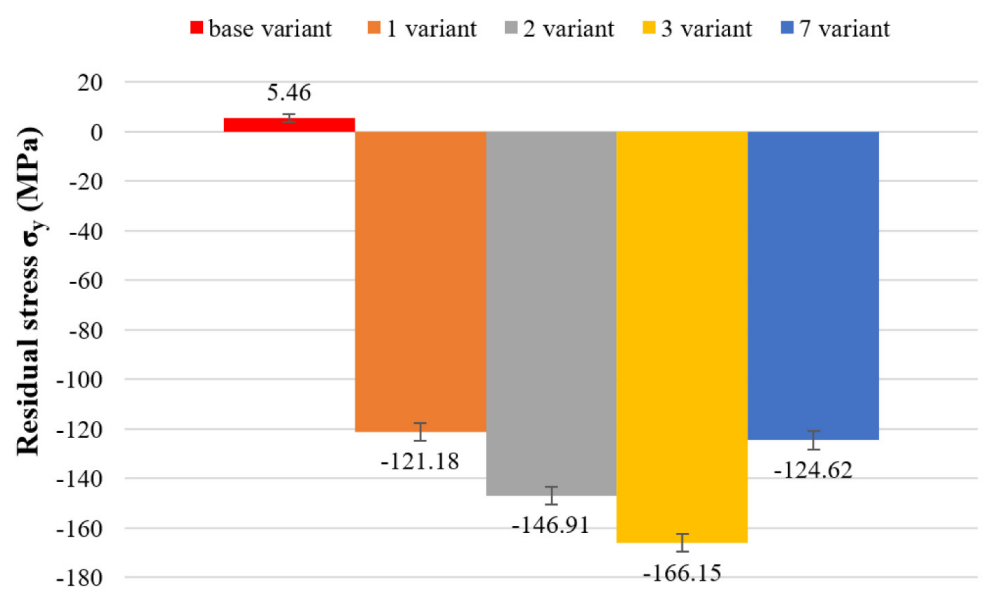

Fig. 4. Residual stress in a longitudinal direction

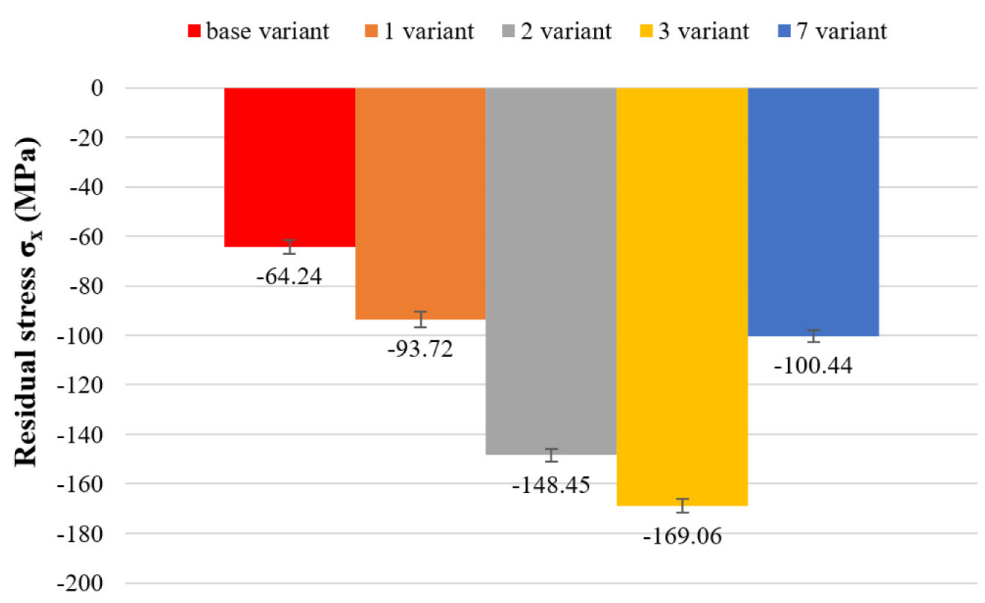

Fig. 5. Residual stress in a transverse direction Microhardness 


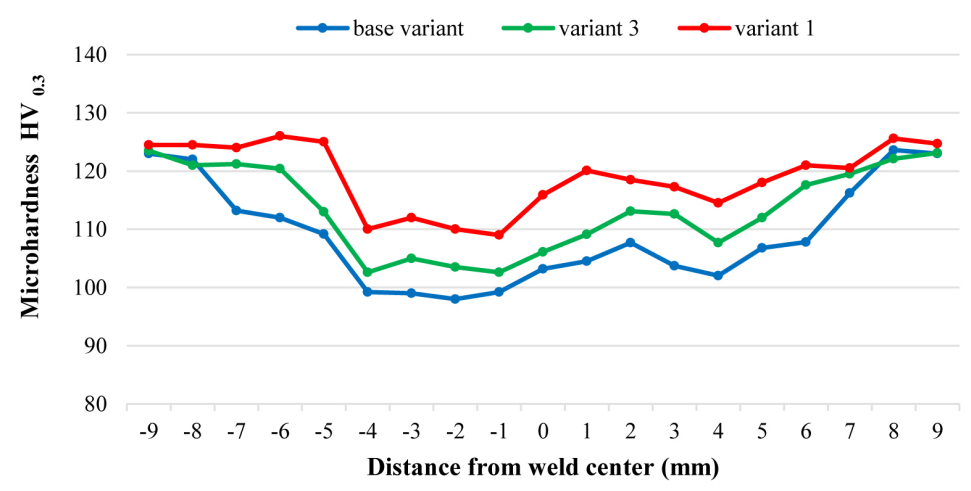

Fig. 6. Microhardness profiles across the weld region for FSW 2024-T3.

the hardness of the heat-affected zone (HAZ), thermo-mechanically affected zone (TMAZ) and weld zone (WZ) increased after SP. Peening pressure is an important parameter that positively affects the microhardness. For the pressure $\mathrm{p}=0.6 \mathrm{MPa}$ (variant 1 ), the average microhardness in WZ increased by $2.4 \mathrm{HV}$ in comparison to the base variant, and by $2 \mathrm{HV}$ compared to the variant $3(\mathrm{p}=0.4 \mathrm{MPa})$. A decrease in the microhardness - typical for this process - ranging from 3.5 to $15 \mathrm{HV}$ can observed in HAZ.

\section{CONCLUSIONS}

The results show that shot peening is a highly efficient and cost-effective mechanical treatment used for improving the mechanical properties of butt joints made with the FSW method. In summary, it can be concluded that the use of glass beads with the granulation of $500 \div 900 \mu \mathrm{m}$ significantly reduced the surface roughness, caused high compressive residual stresses and increased the microhardness of the surface layer. The best results were obtained for the samples peened at the time $\mathrm{t}=3$ min under the pressure $\mathrm{p}=0.4 \mathrm{MPa}$ (variant 3 ). In this case, the surface roughness was reduced to $\mathrm{Ra}=1.42 \mu \mathrm{m}$ and $\mathrm{Rz}=8.05 \mu \mathrm{m}$, compared to the base variant of $\mathrm{Ra}=5.2 \mu \mathrm{m}$ and $\mathrm{Rz}=24.2 \mu \mathrm{m}$, respectively. SP also provides compressive residual stresses $\sigma_{\mathrm{y}}=-166.15 \mathrm{MPa}$ and $\sigma_{\mathrm{x}}=-169.06 \mathrm{MPa}$ (variant 3) which are increased by about $31-62 \%$ in the transverse direction and about $95-97 \%$ in the longitudinal direction compared to welding of butt joints. Shot peening positively affects microhardness. It has increased by $2.4 \mathrm{HV}$ in WZ in comparison to the joint after welding with the FSW method. The conducted research plan PS/DC $3^{2}$ pointed out that both analyzed technological parameters of the pneumo shot peening process have a significant impact on the surface roughness after welding.

\section{REFERENCES}

1. Sue J. Q., Nelson T.W., Mishra R., Mahoney M.: Microstructural investigation of friction stir welded 7050- T651 aluminum. Acta Materialia 51, 2003, p. 713-29.

2. Hatamleh O., DeWald A.: An investigation of the peening effects on the residual stresses in friction stir welded 2195 and 7075 aluminum alloy joints. Journal of Materials Processing Technology 209, 2009, p. 4822-4829.

3. Bucior M., Kubit A., Stachowicz F., Zielecki W.: The impact of heat treatment and shot peening on the fatigue strength of $51 \mathrm{CrV} 4$ steel. Procedia Structural Integrity. 2016, Vol. 2, p. 3330-3336.

4. Takahashi K., Osedo H., Suzuki T., Fukuda S.: Fatigue strength improvement of an aluminum alloy with a crack-like surface defect using shot peening and cavitation peening. Engineering Fracture Mechanics 193, 2018, p. 151-161.

5. Ali A., An X., Rodopoulos C. A., Brown M.W., O'Hara P., Levers A., Gardiner S.: The effect of controlled shot peening on the fatigue behavior of 2024-T3 aluminium friction stir welds. International Journal of Fatigue 29, 2007, p. 1531-1545.

6. Hatamleh O., Lyons J., Forman R.: Laser and shot peening effects on fatigue crack growth in friction stir welded 7075-T7351 aluminum alloy joints. International Journal of Fatigue 29, 2007, p. 421-434.

7. Kawashimaa T., Sanoa T., Hirosea A., Tsutsumib S., Masakic K., Arakawad K., Hori H.: Femtosecond Laser Peening of Friction Stir Welded 7075-T73 Aluminum Alloys. Journal of Materials Processing Tech. 262, 2018, p.111-122.

8. Soyama H.: Comparison between the improvements made to the fatigue strength of stainless steel by cavitation peening, water jet peening, shot peening and laser peening. Journal of Materials Processing 
Technology 269, 2019, p. 65-78.

9. Yin F., Liu Y., Xu R., Zhao K., Partin A., Han Q.: Nanograined surface fabricated on the pure copper by ultrasonic shot peening and an energy-density based criterion for peening intensity quantification. Journal of Manufacturing Processes 32, 2018, p. 656-663.

10. Mustafa A. Abdulstaar., Khaled J. Al-Fadhalah., Lothar Wagner.: Microstructural variation through weld thickness and mechanical properties of peened friction stir welded 6061 aluminum alloy joints. Materials Characterization 126, 2017, p. 64-73.

11. Liu P., Sun S., Xu S., Li Y., Ren G.: Microstructure and properties in the weld surface of friction stir welded 7050-T7451 aluminium alloys by laser shock peening. Vacuum 152, 2018, p. 25-29.

12. Hatamleh O., Smith J., Cohen D., Bradley R.: Surface roughness and friction coefficient in peened friction stir welded 2195 aluminum alloy. Applied Surface Science 255, 2009, p. 7414-7426.
13. Korzyński M.: Experiment methodology. WNT. Warsaw, 2013 (in Polish).

14. PN-EN ISO 4287: 1999. Geometrical product specifications (GPS). Surface texture: Profile method. Terms. definitions and surface texture parameters.

15. Bonarski J. T.: Measurement and use of the texture-stress microstructure characteristics in materials diagnostics. Institute of Metallurgy and Materials Science of the Polish Academy of Sciences. Cracow, 2013 (in Polish).

16. Skrzypek S. J.: New possibilities of measuring macro stress of materials using X-ray diffraction in the geometry of a constant angle of incidence. Publisher AGH. Cracow, 2002 (in Polish).

17. Kłysz S.: Basics of strength of materials. Publisher: Technical Institute of Air Forces. Warsaw, 2015 (in Polish).

18. PN-EN ISO 6507 - 1: 2005. Metals. Hardness measurement using the Vickers method. 